\title{
The impact of the walking dead video game on students' reading comprehension on narrative text
}

\author{
Muhammad Husnun Nadhif \\ Department of English Education, Universitas Negeri Surabaya, Indonesia \\ Muhammad.17020084033@mhs.unesa.ac.id \\ *) correspondence: muhammad.17020084033@mhs.unesa.ac.id
}

\begin{abstract}
With the development of technology every time, the development of media for learning is also overgrowing. Many new media are popping up especially digital-based media, ranging from images, audio, and video. All of that media has been widely used by teachers to get students excited about what they will learn in class. However, the longer these media feel boring for students, the teachers also have to twist their brains to find new media, one of which is video games. Several studies have looked into the influence of adventure video games on learning English; however, few studies have looked into the effect of adventure games on learning English. This study aimed to see how video games affected students' reading comprehension of narrative text. The study consisted of 50 students from SMA Negeri 1 Kebomas Gresik in tenth grade. X-IPS 1 and X-IPS 2 were the class examples. The impact of video games can be reflected in the multiple-choice scores of students. The author used a quantitative procedure and quasi-experimental design as the analysis methodology with a purposive sampling approach. A multiple-choice test was used as the testing tool. The findings in this study explain that video games do not significantly impact students but only increase the motivation of students to learn and entertain students only.
\end{abstract}

Keywords: video games; reading comprehension; narrative text

\section{INTRODUCTION}

One of the essential skills that students must have when studying English is the ability to read. Students become frustrated when given long texts or stories to read for an exam. When a teacher is unable to build a more positive and enjoyable environment, this issue arises. Because of these issues, teachers must use the media as a learning intermediary for students in order for learning to be interesting.

According to the National Reading Council, reading is a complicated method that necessitates various instructional approaches (Healy, 2002). Furthermore, according to Tiedeman, Vygotsky, and Wartofsky, two types of instruments or media can be used in reading: authentic items like books or text, and icons, or abstract signs in an illustration or alphabetical order (Tiedemann, 2011). means that reading is a mechanism in which the minds routinely receive input from the object being interpreted and interpret it based on the readers' previous knowledge of the symbols and alphabet, even illustration. Reading entails interaction with the reader's opinions and understanding, as well as the texts being read. Consequently, since they may have different context information and thoughts on the text they read, the effects of one understanding may vary from that of another.

In general, teachers' responsibility in the teaching and learning process is to help their students by using a variety of varieties to transform important consumers into media outlets. Every student is exposed to a variety of media, including books, the internet, film, and other forms of entertainment. Teachers also use the media to pique students' interest in reading. Many students have been bored when reading text from mainstream media such as novels or short stories. In this case, the video game can represent the text subject for the teacher, which can be a challenge for the teacher himself to make video games a new literacy language for students(Bacalja, 2018). The use of video game as media itself is to reflect and present a combination of text, audio, video, and tooling that allows students that be player to take part in an action or interact with AI on the game, manage resources and achieve their 
goal while they complete several missions (Costikyan, 2002; Djaouti, Alvarez, Jessel, Methel, \& Molinier, 2008; Stenros, 2017).

Video games have become one part of entertainment for Indonesian people, both young people, and adults. Tommy Renato, a manager of one of the digital wallet companies in Indonesia, said that about 100 million people had played video games by 2020. The number of gamers make Indonesia becomes the country with the huge number of gamers in Southeast Asia. Some players are usually affected by the many e-sports tournaments and content creators on the internet who talk about video games. It makes the interest of Indonesian residents, both old and young, especially students who belong to the younger group, play video games especially for entertainment. By enjoying the game, they will not have high pressure in the learning activities (Butler, 2015).

The growing popularity of digital video games has prompted researchers to look into their educational potential. The influence of video games on foreign language learning is no longer remarkable. Some researchers recommend using video games as a tool for students to learn English and develop their literacy skills (Barr, 2018; Hamari et al., 2016; Reinhardt \& Sykes, 2014). According to studies, video games positively impact student literacy growth, especially in listening and reading. Also, words in games are associated with visuals, acts, aims, and dialogue, rather than just meanings or other words. Learners see how words relate to the world's meanings or circumstances they are interested in and how they can help construct or exploit them. Learners with a solely auditory interpretation of chat and messages will just 'cash out' phrases for phrases. It is ideal for passing tests, so it is not good for comprehension. They have profound knowledge and true learning if they can 'cash out' terms for pictures, memories, acts, aspirations, and conversation - for a virtual theatre of inspired action in their heads (Reinders, 2012).

As software video games combine multimedia and other technologies such as network or internet connection, it can make players worldwide enable to experience virtual environments in the video game itself (Connolly, Standfield, \& Boyle, n.d.). Some studies have proposed computer simulation games to include context-rich, cognitively challenging interactive worlds for language learning. For example, Ranalli (2008) investigated the effect of the Sims game on second language vocabulary learning and discovered that participants improved their vocabulary skills statistically significantly.

Parsayi and Soyoof (2018) also investigated what factors affected students' comprehension of narrative text in a video game. Ten EFL and ESL students are experts in playing video games, specifically the games used in this study. The results of using the Metro 2033 video game show that video games with exciting story settings inspire students and help them develop their listening and reading skills, especially when it comes to narrative text.

Chen and Yang (2013) also conducted a study to determine the impact of commercial video games, BONE, on their language learning and their perceptions about the game. Researchers conducted two different studies on video games and language learning. In the first study, students experienced an increase in vocabularies, but there was no significant increase in their learning performance. The second study focused on examining the weaknesses and strengths of using video games as a language learning medium. The results of this research can be seen that video games have their strengths and weaknesses. The small number of subjects is a big drawback. With a greater sample size, the study findings will be more representative. Also, the result of this study is that the video game itself only affects specific skills.

Permatasari (2013) also looked into the usage of video games to help students enhance their writing skills. Researchers performed a study for junior high school students to determine their capacity to write text narratives, and they used two tests to evaluate student development: a pre-test and a post-test. Fairy Tail video as a medium in writing class was shown to be effective in this study, particularly for the VIII-A of SMP N 24 Semarang. During the teaching and learning process, the students also stated that they were not bored. After utilizing video, they had more enjoyment and were more motivated to compose narrative writings. 
In this study, the video game used is The Walking Dead Season one (2012); this game is based on the walking dead comic itself published in 2003. The game is set in the same fictional world as the comic, with events soon after the Georgia zombie outbreak. Some characters from the original comic series make cameo appearances in the game as well. Lee Everett, a university professor, and imprisoned criminal, rescues and cares for a young child in the game.

Based on the background of the study, the researcher formulated the research questions as follows: Does the use of the walking dead video game have a positive impact on students' reading comprehension in the narrative text?

This study aimed to obtain evidence that commercial video games such as the walking dead can positively impact high school students, especially for reading comprehension to narrative text.

\section{METHODS}

To solve problems that had been posed in the introduction, the researcher used the QuasiExperimental Design approach. The population will self-select to (or their providers will pick on their behalf) one of many distinct treatment groups for the aim of assessing the real-world effectiveness and safety of those non-randomized therapies in a prospective or retrospective research (Maciejewski, 2020). Researchers used experimental analysis to assess the impact of an interaction between two given variables. This study utilizes quasi-experimental methods, which enable variables to be controlled or manipulated. Since it remembers the condition of research materials, which also does not allow random tasks, quasi-experimental usage is used. It occurs as a result of forming a whole group (naturally formed entire group), such as a class of students. These classes are often frequently small in size. Since the regulation of factors relating to the test subject cannot be achieved entirely under these cases, the laws of the actual experiment cannot be met.

The study will take place in SMAN 1 Kebomas Gresik since it will be done on senior high school students, mostly 10th-grade students, and will include about 50 students. Students will be split into two classes in this study, each of 25 students: experimental and control. Both groups will be asked the same tests, but the procedure will be different. The experimental group will receive treatment in the form of a video game called The Walking Dead, while the control group will receive treatment in narrative text with the same story as the video game itself.

Researchers will use a video game called The Walking Dead season 1 as the media for the treatment. Since there are currently few instructional adventure games for language learning, a noneducational commercial game was selected. A good language learning game can have plenty of language feedback as well as a fun game design. The Walking Dead game allows players to hear native speaker speech and display English subtitles simultaneously while playing. The game also features good graphics and sound effects, as well as a fun game mission style. Players can take part in various challenging challenges to read the text carefully to solve the puzzles. Furthermore, the game is simple to play, even for inexperienced video gamers. Each episode has an exciting and thrilling storyline, and each episode in the game has also fulfilled the generic structure of narrative text such as orientation, complication, resolution, and reorientation.

In the gameplay, players/students are instructed to use a third-person view and a range of dramatic camera angles while playing. Some portions of the game demand the player to respond in a certain amount of time, leading to critical decisions influence on the story. Some dialogue trees demand the player to decide within a certain amount of time, or else he will remain silent, which might affect how the other characters react to him.

In the pre-test, students will be given ten narrative texts and five questions each. Students will then be given treatment to play and read a narrative text about the game and answer questions from the text. This media is used in classroom learning and a task for students to summarize and understand the video game. It is done to improve the ability of students to read and comprehend narrative text well. The results of this pre-test are used to determine the students' initial ability to know the level of reading of the students so that there is no significant difference if the next activity is carried out. Posttest is done to give researchers the results of evaluation after treatment on participants. A post-test 
also uses the same number of questions and mechanisms as a pre-test. A post-test aims to provide researchers with the outcomes of an experiment after participants have received treatment. (Chu, PH. and Chang, 2017).

The researcher uses tests to collect information/data from the students (Pre-test and posttest). Since tests offer substantial knowledge about what students know and should do, the researcher chose to use them. The t-test statistical analysis will be used in this study. This method compares the test effects of two groups separated, respectively the Control and Experimental groups.

As a result, the researcher used a comparative t-test analysis to compare both groups between pre-test and post-test. The researcher used IBM SPSS Statistic Version 25 for this step. Statistical Package for the Social Sciences is abbreviated as SPSS. This software can be used to review data gathered from observations, polls, and experiments, among other sources. It can display data analysis variations and presentation functions, such as graphical data presentation and statistical analysis.

\section{RESULTS AND DISCUSSION}

\section{Normality test}

A normality test is used to know whether the data collected are normal on the distribution or not. Since the sample size is 25 , less than 50 , the researcher used Shapiro-Wilk to assess normality. The test results reveal that both classes' pre-test and post-test scores were normally distributed (see Table 1 and Table 2). As a result, the following theories are proposed:

H0: Data of X follows a normal distribution.

H1: Data of X did not follow a normal distribution.

If the significant value of the Shapiro-Wilk Test is greater than the significant value of $\mathrm{H} 0$, the hypothesis is accepted $(0,05)$.

TABLE 1. Tests of Normality (Pre-test)

\begin{tabular}{lllllll}
\hline & \multicolumn{5}{l}{ Kolmogorov-Smirnov $^{\mathrm{a}}$} & \multicolumn{3}{c}{ Shapiro-Wilk } \\
\cline { 2 - 7 } & Statistic & $\mathrm{df}$ & Sig. & Statistic & df & Sig. \\
\hline Experimental Class & .164 & 25 & .080 & .937 & 25 & .125 \\
Control Class & .101 & 25 & $.200^{*}$ & .962 & 25 & .448 \\
\hline
\end{tabular}

TABLE 2. Tests of Normality (Post-test)

\begin{tabular}{lllllll}
\hline & \multicolumn{5}{l}{ Kolmogorov-Smirnov $^{\mathrm{a}}$} & \multicolumn{4}{l}{ Shapiro-Wilk } \\
\cline { 2 - 7 } & Statistic & $\mathrm{df}$ & Sig. & Statistic & df & Sig. \\
\hline Experimental Class & .178 & 25 & .040 & .930 & 25 & .085 \\
Control Class & .163 & 25 & .087 & .937 & 25 & .123 \\
\hline
\end{tabular}

Based on the two tables above, the significant value of the overall test, either from the experimental or control class above 0.05 , which is significant from experimental, is 0.125 (pre-test) and 0.085 (post-test). Similarly, the control class that gets significant 0.448 (pre-test) and 0.123 (posttest). It indicates that $\mathrm{H} 0$ is acceptable and that the data are distributed normally for both tests.

\section{Homogeneity test}

After determining data normality, the researcher must determine data homogeneity. It will be determined using the Descriptive Statistic formula in the SPSS 25 program, whether homogeneous or heterogenic. The theories and findings are listed below.

Hypothesis:

H0: The experimental class sample is the same as the controlled class sample, or the sample is homogeneous.

H1: The experimental class sample differs from the control class sample, or the sample is heterogeneous.

TABLE 3. Test of Homogeneity of Variances 
The impact of the walking dead video game on students reading comprehension on narrative text

Pre-test Score

\begin{tabular}{llll}
\hline Levene Statistic & df1 & df2 & Sig. \\
\hline .011 & 1 & 48 & .917 \\
\hline
\end{tabular}

TABLE 4. Test of Homogeneity of Variances

Post-test Score

\begin{tabular}{llll}
\hline Levene Statistic & df1 & df2 & Sig. \\
\hline 1.140 & 1 & 48 & .291 \\
\hline
\end{tabular}

For the homogeneity test, both tests have significance above 0.05 , which is the significant standard on the homogeneity test. The table above explained that the pre-test has a significant value $(0.917>0.05)$ and post-test $(0.291>0.05)$, which both qualify for hypothesis $\mathrm{H} 0$, which is both data submitted homogenous.

\section{Data analysis}

TABLE 5. Group Statistics

\begin{tabular}{lllllll}
\hline & Group & N & Mean & $\begin{array}{l}\text { Std. } \\
\text { Deviation }\end{array}$ & $\begin{array}{l}\text { Std. } \\
\text { Mean }\end{array}$ & Error \\
\hline Student's Gained Score & Experimental & 25 & 7.76 & 8.705 & 1.741 \\
& Control & 25 & 6.00 & 9.381 & 1.876
\end{tabular}

The mean score and the standard deviation of both classes concerning the subjects' perceptions were calculated, for the experimental class $(\mathrm{M}=7.76, \mathrm{SD}=8.71)$, the control class was calculated $(\mathrm{M}=6$, $\mathrm{SD}=9.38)$. The table above also mentioned standard error in each class, as in the experimental class $(\mathrm{SE}=1.74)$ and Control Class $(\mathrm{SE}=1.88)$. All of this will be processed to the next stage that calculates related determining the standard error of the different mean of variable Experimental and mean of variable control. Also, after that, the t-test calculation process is done to prove which hypotheses are correct and accepted.

\section{Hypothesis testing}

TABLE 6. Independent Samples Test

\begin{tabular}{|c|c|c|c|c|c|c|c|c|c|c|}
\hline & & \multicolumn{2}{|c|}{$\begin{array}{l}\text { Levene's Test } \\
\text { for Equality of } \\
\text { Variances }\end{array}$} & \multicolumn{4}{|c|}{ t-test for Equality of Means } & \multirow{3}{*}{$\begin{array}{l}\text { Std. Error } \\
\text { Difference }\end{array}$} & \multirow{2}{*}{\multicolumn{2}{|c|}{$\begin{array}{l}95 \% \text { Confidence } \\
\text { Interval of the } \\
\text { Difference }\end{array}$}} \\
\hline & & \multirow[t]{2}{*}{$\mathrm{F}$} & \multirow[t]{2}{*}{ Sig. } & \multirow[t]{2}{*}{$\mathrm{t}$} & \multirow[t]{2}{*}{$\mathrm{df}$} & \multirow[t]{2}{*}{$\begin{array}{l}\text { Sig. (2- } \\
\text { tailed) }\end{array}$} & \multirow[t]{2}{*}{$\begin{array}{l}\text { Mean } \\
\text { Difference }\end{array}$} & & & \\
\hline & & & & & & & & & Lower & Upper \\
\hline \multirow[t]{2}{*}{$\begin{array}{l}\text { Student's } \\
\text { Gained } \\
\text { Score }\end{array}$} & $\begin{array}{l}\text { Equal } \\
\text { variances } \\
\text { assumed } \\
\end{array}$ & .623 & .434 & .688 & 48 & .495 & 1.760 & 2.559 & -3.386 & 6.906 \\
\hline & $\begin{array}{l}\text { Equal } \\
\text { variances } \\
\text { not } \\
\text { assumed }\end{array}$ & & & .688 & 47.734 & .495 & 1.760 & 2.559 & -3.387 & 6.907 \\
\hline
\end{tabular}

After calculation, the table above shows that the t-test calculation of $t$ was 0.69 , and the degree of freedom (df) is 48 . Furthermore, the degree significance used in this study was $5 \%$, or 0.05 , while in the table, the value is 1.67. The value of $\mathrm{t}$ (observation) was lower than the result of the $\mathrm{t}$-table. So, this study showed that the use of video games on learning narrative text students SMAN 1 Kebomas Gresik does not significantly impact the understanding of narrative text. 
From the research result, there is no significant development in students' test scores; this is usually influenced by students' proficiency in English, which affects their motivation to understand narrative text after treatment. From Mayer (2019), multimedia must have the necessary elements and add multimedia motivation and metacognition. Motivation affects the willingness of students to understand the video game and will later influence the next storyline. It affects students to understand the narrative side of the video game. At the same time, metacognition refers to keeping track of the cognitive processes of choosing, arranging, and incorporating information and managing and adapting these processes as required to meet the learning target. These two aspects are very influential to a learning system like this.

The finding of this research also different from the previous studies earlier. In this research, the sample were students with limited skills in English. Also, some students have low motivation. They think that the game is too difficult to understand because they have limited skills and vocabulary. It is proved that learning English via video game was motivating, but the limited English skill challenge students to comprehend the narrative text; this makes students unable to organize and manage the decisions made in the game and makes them play in vain. The finding of the study was not the same as the one used in this study; all later studies used funny (BONE from Chen and Yang, and Fairy Tail from Permatasari), simulation games (The Sims Ranalli), and Action shooting games (Metro 2044 from Parsayi and Soyoof). Because of the difference between variations of sample knowledge and game used in tests, the results of this study differed from those that have similar studies

\section{CONCLUSION}

This quasi-experimental study was performed in the academic year 2020/2021 to obtain observational data regarding the impact of video games on students' reading comprehension of narrative text at SMAN 1 Kebomas Gresik tenth grade students. Based on mathematical calculations and hypotheses checking with the significance level of $5 \%$, the conclusion concludes that $t$ observation $<\mathrm{t}$ table or $(0.69<1.677)$. It suggests that in the tenth grade of SMA Negeri 1 Kebomas Gresik, video games had no significant influence on students' reading comprehension of narrative text. Even if the statistic indicates no substantial impact, the students' post-test scores tended to be significantly higher than their pre-test result, and they were very willing to use a video game as a learning tool for EFL.

There are suggestions for persons who want to study in the same area, based on the conclusion above. Students should use another medium to learn English as a foreign language that will also be entertaining them while improving their reading skills, especially with Narrative Text. Meanwhile, teachers can continue to conduct extensive research into teaching methods that can benefit students' learning. It is expected for teachers to prefer video games that make it easier for students to understand the use of their language by the level of English proficiency of the student and also not burden students in other matters such as the large size of the game and the ability of the device of the student.

\section{REFERENCES}

Bacalja, A. (2018). What Critical Literacy Has to Offer the Study of Video Games. Australian Journal of Language and Literacy, 41(3), 155.

Barr, M. (2018). Student attitudes to games-based skills development: Learning from video games in higher education. Computers in Human Behavior, 80, 283-294. https://doi.org/10.1016/j.chb.2017.11.030

Butler, Y. G. (2015). The use of computer games as foreign language learning tasks for digital natives. System, 54, 91-102. https://doi.org/10.1016/j.system.2014.10.010

Chen, H. J. H., \& Yang, T. Y. C. (2013). The impact of adventure video games on foreign language learning and the perceptions of learners. Interactive Learning Environments, 21(2), 129-141. https://doi.org/10.1080/10494820.2012.705851

Chu, PH. and Chang, Y. (2017). John W, Creswell, Research Design: Qualitative, Quantitative, and Mixed Methods Approaches. Journal of Social and Administrative Sciences, 4(June), 3-5.

Connolly, T., Standfield, M., \& Boyle, L. (n.d.). Games-Based Learning Advancements for Mult - Thomas 
Connolly.

Costikyan, G. (2002). I Have No Words but I Must Design: Toward a Critical Vocabulary for Games. Computer Games and Digital Cultures Conference, 9-33. Retrieved from http://scholar.google.com/scholar?hl=en\&btnG=Search\&q=intitle:I+Have+No+Words+\&+ I+Must+Design+:+Toward+a+Critical+Vocabulary+for+Games $\# 0 \% 5$ Cnhttp:/ / andrey.savel yev.2009.homepage.auditory.ru/2006/Ivan.Ignatyev/DiGRA/I Have No Words \& I Must Design_Toward a

Djaouti, D., Alvarez, J., Jessel, J.-P., Methel, G., \& Molinier, P. (2008). A Gameplay Definition through Videogame Classification. International Journal of Computer Games Technology, 2008, 1-7. https://doi.org/10.1155/2008/470350

Hamari, J., Shernoff, D. J., Rowe, E., Coller, B., Asbell-Clarke, J., \& Edwards, T. (2016). Challenging games help students learn: An empirical study on engagement, flow and immersion in gamebased learning. Computers in Human Behavior, 54, 170-179. https://doi.org/10.1016/j.chb.2015.07.045

Healy, C. (2002). Reading: What the Experts Say. Parent Educational Advocacy Training, 1-3.

Maciejewski, M. L. (2020). Quasi-experimental design. Biostatistics and Epidemiology, 4(1), 38-47. https://doi.org/10.1080/24709360.2018.1477468

Mayer, R. E. (2019). Computer Games in Education. Annual Review of Psychology, 70(1), 531-549. https://doi.org/10.1146/annurev-psych-010418-102744

Parsayi, F., \& Soyoof, A. (2018). Video games: The interface between langugae learning and storytelling. International Journal of Pedagogies \& Learning, 13(2), 103-118.

Permatasari, D. (2013). English Language Teaching Forum The Use of Video as a Medium to Improve Students' Ability in Writing Narrative. English Language Teaching Forum, 2(1), 1-11.

Ranalli, J. (2008). Learning English with the Sims: Exploiting authentic computer simulation games for L2 learning. Computer Assisted Language Learning, 21(5), 441-455. https://doi.org/10.1080/09588220802447859

Reinders, H. (2012). Digital Games in Language Learning and Teaching. In Digital Games in Language Learning and Teaching. https://doi.org/10.1057/9781137005267

Reinhardt, J., \& Sykes, J. M. (2014). Digital game and play activity in L2 teaching and learning. Language Learning and Technology, 18(2), 2-8.

Stenros, J. (2017). The Game Definition Game: A Review. Games and Culture, 12(6), 499-520. https://doi.org/10.1177/1555412016655679 